\title{
Odd Configurations in Neutral Nickel (Niı)*
}

\author{
Charles Roth**
}

\begin{abstract}
(May 28, 1970)
Experimental levels of the configurations $3 d^{9} 4 p, 3 d^{8} 4 s 4 p$ and $3 d^{9} 5 p$ of Ni I were compared with corresponding calculated values. The electrostatic interactions between the configurations $(3 d+4 s)^{9} 4 p$ as well as between $3 d^{8} 4 s 4 p$ and $3 d^{9} 5 p$ were considered explicitly.

For the configurations $(3 d+4 s)^{9} 4 p, 71$ experimental levels were fitted by means of 17 free parameters to yield an rms error of $131 \mathrm{~cm}^{-1}$. On fitting 83 levels of the configurations $3 d^{9} 4 p+3 d^{8} 4 s 4 p+3 d^{9} 5 p$ by means of 25 free parameters an rms error of $147 \mathrm{~cm}^{-1}$ was obtained.
\end{abstract}

Key words: Energy levels; $g$-factors; interactions between configurations; nickel; $(3 d+4 s)^{9} 4 p$; $3 d^{9} 4 p+3 d^{8} 4 s 4 p+3 d^{9} 5 p$.

\section{The Configurations $(3 d+4 s){ }^{9} 4 p$}

The configurations $(d+s)^{9} p$ comprise 92 terms splitting into 212 levels. In AEL [1] ${ }^{1}, 27$ terms splitting into 66 levels are assigned to the configurations $3 d^{9} 4 p$ $+3 d^{8} 4 s 4 p$, and in addition, there are 6 unclassified odd levels. As in Co I [7], only the initial values for the parameters ${ }^{2} B^{\prime}, C^{\prime}$, and $\alpha^{\prime}$, were obtained by linear extrapolation from the results of Sc I-Co I [2-7]. Then,

$$
\begin{aligned}
& B^{\prime}=1040 \\
& C^{\prime}=4140 \\
& \alpha^{\prime}=84
\end{aligned}
$$

The initial values of the other parameters were taken as the final values of Co I [7].

The initial value for the height of the configuration $3 d^{8} 4 s 4 p$ can be obtained either from the electrostatic matrices of ${ }^{5} \mathrm{~F}$ or ${ }^{5} \mathrm{G}$ (they only differ by $\left.4 F_{2}^{\prime}\right)$. Then from ${ }^{5} \mathrm{G}$, we have [1], [8]

$$
{ }^{5} \mathrm{G}_{\text {C.G. }}=A^{\prime}-8 B^{\prime}-2 G_{d s}^{\prime}-F_{2}^{\prime}-G_{p s}^{\prime}+12 \alpha^{\prime}=27900
$$

Hence, from the values of the previously determined parameters

$$
A^{\prime}=45670
$$

The height of the configuration $3 d^{9} 4 p$ was obtained from the electrostatic matrix of $3 d^{9} 4 p^{3} \mathrm{P}$, since the

\footnotetext{
*An invited paper.

**Present address: Department of Mathematics, McGill University, Montreal 110 , Canada.

${ }^{1}$ Figures in brackets indicate the literature references at the end of this paper.

${ }^{2}$ Unprimed parameters refer to the configuration $3 d^{9} 4 p$, primed parameters to $3 d^{8} 4 s 4 p$, and doubly primed to $3 d^{7} 4 s^{2} 4 p$.

The numerical values of all levels and parameters are in $\mathrm{cm}^{-1}$.
}

terms ${ }^{3} \mathrm{P}$ of $3 d^{8} 4 s 4 p$ are sufficiently high that the interaction with them is not strong.

Then, since

$$
3 d^{9} 4 p z^{3} \mathrm{P}_{\text {C.G. }}=A-7 F_{2}=29330
$$

initially,

$$
A=30870
$$

It should be noted that the above value of $A$ contains the contribution $6 \alpha$, since the constant matrix of $\alpha$ for $d^{9} p$ was not put on tape.

The parabola used to find D" (Co I) [7], extrapolated further gives

$$
D^{\prime \prime}[\mathrm{Ni} \text { I }]=48300
$$

By using the values of $B^{\prime \prime}$ and $C^{\prime \prime}$ from $\mathrm{V}_{\mathrm{I}}$ to $\mathrm{Co}_{\mathrm{I}}$ $[3-7]$ in order to obtain the best straight lines for these parameters, and extrapolating to $\mathrm{Ni}$ I

$$
\begin{aligned}
& B^{\prime \prime}=1190 \\
& C^{\prime \prime}=4190
\end{aligned}
$$

Then, from eqs (8) and (9), [5]

$$
A^{\prime \prime}=85680
$$

The final values of the parameters obtained in the uniform treatment ${ }^{3}$ are given in table 1 .

The final value of $A^{\prime \prime}$ was fixed at 85060 , so that with the new values of the parameters, $D^{\prime \prime}$ (Ni I) should approximately equal the original value of 48300 .

3 The parameters $A, A^{\prime}, G_{d s}^{\prime}$, and $G_{\nu s}^{\prime}$ are allowed to change freely. The parameters $B, C, F_{2}$, and $G_{1}$ are in arithmetic progression. The parameters $G_{3}, \alpha, \zeta_{d}$, and $\zeta_{p}$ are kept equal, and for the parameters of the interactions between configurations $H^{\prime}$ is kept equal to $H, J^{\prime}$ to $J, G$ to $G_{d s}^{\prime}$ and $K^{\prime}=K+956$ (fixed difference). 
From the values of $B^{\prime}, B^{\prime \prime}, C^{\prime}$, and $C^{\prime \prime}$ obtained for first spectra investigated previously it was apparent that the approximate differences were:

$$
\begin{aligned}
& B^{\prime \prime}-B^{\prime}=85 \\
& C^{\prime \prime}-C^{\prime}=100
\end{aligned}
$$

These differences were kept fixed in the leastsquares calculations.

In order to estimate the effects of the interactions with the configurations $3 d^{7} 4 s^{2} 4 p$, the configurations $3 d^{9} 4 p+3 d^{8} 4 s 4 p$ were also considered without $3 d^{7} 4 s^{2} 4 p$. Although $3 d^{7} 4 s^{2} 4 p$ is very high, the rms error rose from the present value of 131 to 173 , stressing the importance of inserting the interactions with $3 d^{7} 4 s^{2} 4 p$ explicitly. Although all the levels had higher deviations without $3 d^{7} 4 s^{2} 4 p$, the level ${ }^{3} \mathrm{~F}\left({ }^{1} \mathrm{P}\right) y^{3} \mathrm{G}_{5}{ }^{4}$ can be singled out in particular. Whereas in the case of $(3 d+4 s)^{9} 4 p$ the deviation for this level was 330 , for $3 d^{9} 4 p+3 d^{8} 4 s 4 p$ the deviation rose to 540 . The final parameters for $3 d^{9} 4 p+3 d^{8} 4 s 4 p$ are given in table 1 .

Since it was not possible to perform a variation in the least-squares with $A^{\prime \prime}$ free, the calculated values of the levels $3 d^{7} 4 s^{2} 4 p$ are not significant. The comparison of the experimental and calculated values of the levels and the $g$-factors of the configurations $3 d^{8} 4 p+3 d^{7} 4 s 4 p$ are given in table $\mathrm{A}$ of the appendix, when these configurations were considered together with $3 d^{9} 5 p$.

\section{2. $\mathrm{Ni}$ I $-3 d^{9} 4 p+3 d^{8} 4 s 4 p+3 d^{9} 5 p$}

All the predicted levels of the configuration $3 d^{9} 5 p$ have been observed experimentally. Furthermore, since the configuration $3 d^{95} p$ lies in the middle of the range of observed levels of $3 d^{8} 4 s 4 p$, it is interesting to investigate the effect of the interaction between $3 d^{8} 4 s 4 p$ and $3 d^{9} 5 p$. The necessary matrices comprising the configurations $d^{9} p, d^{8} s p, d^{9} p^{\prime}$ and the interactions $d^{9} p-d^{8} s p$ and $d^{9} p^{\prime}-d^{8} s p$ had already been lculated for Cu II [9].

The initial values for the parameters of $3 d^{9} 4 p$ $+3 d^{8} 4 s 4 \mathrm{p}$ were taken as the final values obtained for $\mathrm{Ni}$ I $(3 d+4 s)^{9} 4 p$.

For $3 d^{9} 5 p$, the initial values of $A^{* 5}$ and $F_{2}^{*}$ were obtained from the electrostatic matrices of ${ }^{3} \mathrm{P},{ }^{3} \mathrm{D}$, and ${ }^{3} \mathrm{~F}$. By using the centers of gravity of the three terms and least-squares to reduce the 3 equations in 2 unknowns to 2 equations in 2 unknowns the solution gives

$$
\begin{aligned}
& A^{*}=49260 \\
& F_{2}^{*}=37
\end{aligned}
$$

Since the matrices of $J$ equal to 0 and 4 are of order 1 , we obtain from ${ }^{3} \mathrm{P}_{0},{ }^{3} \mathrm{~F}_{4}$, and (10) initially

$$
\begin{aligned}
& \zeta_{d}^{*}=640 \\
& \zeta_{p}^{*}=340
\end{aligned}
$$

\footnotetext{
${ }^{4}$ For the theoretical term designations see the appendix of this paper.

${ }^{5}$ Starred parameters refer to the configuration $3 d^{9} 5 p$.
}

Then, by using the fact that the trace equals the sum of the eigenvalues we obtain from the matrices of $J$ equal to 1 and 3 :

$$
\begin{aligned}
& G_{1}^{*}=95 \\
& G_{3}^{*}=13
\end{aligned}
$$

The above initial values were used at first in the diagonalization of $3 d^{9} 5 p$ alone. After two iterations the following values were obtained:

$$
\begin{array}{rc}
A^{*}=49470 \pm 43 \\
F_{2}^{*}= & 42 \pm 9 \\
G_{1}^{*}= & 73 \pm 10 \\
G_{3}^{*}= & 0 \text { (Fixed) } \\
\zeta_{d}^{*}= & 531 \pm 36 \\
\zeta_{p}^{*} & =159 \pm 82 \\
\text { rms error } & =139.4 \mathrm{~cm}^{-1}
\end{array}
$$

The parameter $G_{3}^{*}$ was eliminated, since it had a value of $-9 \pm 9$ when left to change freely.

Guided partly by the results of $\mathrm{Cu}$ II [9], the initial values for the parameters $J^{*}\left(3 d^{9} 5 p-3 d^{8} 4 s 4 p\right)$ and $K^{*}\left(3 d^{9} 5 p-3 d^{8} 4 s 4 p\right)$ were taken to equal about half of the corresponding values of $J$ and $K$. Then, from table 1

$$
\begin{aligned}
& J^{*}=500 \\
& K^{*}=1000
\end{aligned}
$$

In the final variation of the least-squares all the 33 terms splitting into 78 levels, which are assigned to $3 d^{9} 4 p+3 d^{8} 4 s 4 p+3 d^{9} 5 p$ in AEL, were inserted. In addition, 5 unclassified levels were also included. The values of the parameters for the three configurations are given in table 1.

The parameter $F_{2}^{*}$ was eliminated since it assumed a small negative value when left to change freely.

The values for the parameters $G_{3}, G_{3}^{*}$, and $\zeta_{p}^{*}$ are not meaningful since the standard errors are larger than the numerical values of the parameters.

The values for the parameters $J^{*}$ and $K^{*}$ are important since they provide the only information about the strength of the interaction $3 d^{n} 5 p+3 d^{n-1} 4 s 4 p$ in the first spectra of the iron group.

The calculated values, percentages compositions and $g$-factors of all the 114 predicted levels (50 terms) of $3 d^{9} 4 p+3 d^{8} 4 s 4 p+3 d^{9} 5 p$ are given in table $\mathrm{A}$ (appendix).

The only odd level not included was $3^{\circ}$ at 44336.10 . An examination of the combinations of the level $3^{\circ}$ as given by Russell [10], reveals that this level is based upon combinations with only the two even levels $a^{3} \mathrm{~F}_{3}$ and $a^{3} \mathrm{~F}_{4}$. From table $\mathrm{A}$ it is evident that this level could conceivably be assigned to ${ }^{3} \mathrm{P}\left({ }^{3} \mathrm{P}\right)^{5} \mathrm{D}_{4}$, yielding a deviation of around 300 . However, since it is doubtful whether $3^{\circ}$ is a valid level, this assignment was rejected. 
TABLE 1. Final parameters in units of $\mathrm{cm}^{-1}$

\begin{tabular}{|c|c|c|c|}
\hline Parameter & $(3 d+4 s)^{9} 4 p$ & $3 d^{9} 4 p+3 d^{8} 4 s 4 p$ & $3 d^{9} 4 p+3 d^{8} 4 s 4 p+3 d^{9} 5 p$ \\
\hline$A$ & $31158 \pm 156$ & $30814 \pm 218$ & $31016 \pm 161$ \\
\hline$A^{\prime}$ & $45786 \pm 139$ & $45144 \pm 167$ & $45352 \pm 140$ \\
\hline$A^{\prime \prime}$ & 85060 (Fixed) & & \\
\hline$A^{*}$ & ................. & & $49417 \pm 183$ \\
\hline$B^{\prime}$ & $1024 \pm 7$ & $1017 \pm 10$ & $1011 \pm 9$ \\
\hline$B^{\prime \prime}$ & 1109 (Fixed) & & \\
\hline$C^{\prime}$ & $4187 \pm 54$ & $4202 \pm 73$ & $4112 \pm 66$ \\
\hline$C^{\prime \prime}$ & 4287 (Fixed) & & \\
\hline$F_{2}$ & $166 \pm 13$ & $148 \pm 18$ & $159 \pm 15$ \\
\hline$F_{2}^{\prime}$ & $311 \pm 7$ & $304 \pm 9$ & $315 \pm 8$ \\
\hline$F_{2}^{\prime \prime}$ & 456 (Arith. Progress.) & & \\
\hline$F_{2}^{*}$ & (.......................... & & 0 (Fixed) \\
\hline$G_{1}^{\prime \prime}$ & $165 \pm 9$ & $166 \pm 13$ & $163 \pm 12$ \\
\hline$G_{1}$ & $223 \pm 9$ & $240 \pm 14$ & $251 \pm 13$ \\
\hline$G_{1}^{\prime}$ & 281 (Arith. Progress.) & & \\
\hline$G_{1}^{*}$ & 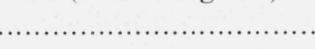 & ............ & $41 \pm 14$ \\
\hline$G_{3}=G_{3}^{\prime}$ & $14 \pm 4$ & $15 \pm 5$ & $15 \pm 6$ \\
\hline$G_{3}^{\prime \prime}=G_{3}^{\prime}$ & 14 (Equal) & & \\
\hline$G_{3}^{*}$ & …............. & & $3 \pm 10$ \\
\hline$G_{d s}^{\prime}$ & $1626 \pm 53$ & $1505 \pm 90$ & $1470 \pm 81$ \\
\hline$G=G_{d s}^{\prime}$ & 1626 (Equal) & & \\
\hline$G_{p s}^{\prime}$ & $7027 \pm 60$ & $6705 \pm 67$ & $6755 \pm 55$ \\
\hline$\alpha^{\prime}$ & $83 \pm 7$ & $81 \pm 11$ & $59 \pm 11$ \\
\hline$\alpha^{\prime \prime}=\alpha^{\prime}$ & 83 (Equal) & & \\
\hline$H$ & $154 \pm 33$ & $159 \pm 64$ & $174 \pm 48$ \\
\hline$H^{\prime}=H$ & 154 (Equal) & & \\
\hline$J$ & $1144 \pm 34$ & $693 \pm 219$ & $1003 \pm 155$ \\
\hline$J^{\prime}=J$ & 1144 (Equal) & & \\
\hline$J^{*}\left(3 d^{9} 5 p-3 d^{8} 4 s 4 p\right)$ & & & $573 \pm 77$ \\
\hline$K$ & $2072 \pm 135$ & $1691 \pm 223$ & $2010 \pm 162$ \\
\hline$K^{\prime}$ & 3028 (Fixed Diff.) & & \\
\hline$K^{*}\left(3 d^{9} 5 p-3 d^{8} 4 s 4 p\right)$ & … & $\cdots \cdots \cdots \cdots$ & $996 \pm 74$ \\
\hline $\begin{array}{l}\zeta_{d}=\zeta_{d}^{\prime} \\
\zeta_{d}^{\prime \prime}=\zeta_{d}^{\prime}\end{array}$ & $\begin{array}{l}603 \pm 19 \\
603 \text { (Equal) }\end{array}$ & $581 \pm 26$ & $600 \pm 22$ \\
\hline $\begin{array}{l}b_{d}=\zeta_{d} \\
\zeta_{d}^{*}\end{array}$ & ................ & & $\begin{array}{l}596 \pm 51 \\
596 \ldots\end{array}$ \\
\hline$\zeta_{p}=\zeta_{p}^{\prime}$ & $255 \pm 51$ & $229 \pm 62$ & $206 \pm 59$ \\
\hline$\zeta_{p}^{\prime \prime}=\zeta_{p}^{\prime}$ & 255 (Equal) & & \\
\hline$\zeta_{p}^{*}$ & ................ & & $51 \pm 120$ \\
\hline rms error & $131.1 \mathrm{~cm}^{-1}$ & $173.3 \mathrm{~cm}^{-1}$ & $147.0 \mathrm{~cm}^{-1}$ \\
\hline
\end{tabular}

There were the following changes in assignment:

1. AEL $3 d^{8} 4 s\left(b^{2} \mathrm{D}\right) 4 p y^{3} \mathrm{P}_{1}$

2. AEL $3 d^{8} 4 s\left(b^{2} \mathrm{D}\right) 4 p x^{3} \mathrm{D}_{2}$

3. ${ }^{3} \mathrm{~F}\left({ }^{1} \mathrm{P}\right)^{3} \mathrm{D}_{3}$

4. AEL $3 d^{8} 4 s\left(b^{2} \mathrm{D}\right) 4 p y^{1} \mathrm{P}$

5. AEL $3 d^{8} 4 s\left(b^{2} \mathrm{D}\right) 4 p x^{1} \mathrm{D}$

6. AEL $3 d^{8} 4 s\left(b^{2} \mathrm{D}\right) 4 p x^{1} \mathrm{~F}$

7. ${ }^{3} \mathrm{~F}\left({ }^{1} \mathrm{P}\right)^{3} \mathrm{~F}_{3}$

8. $5 p^{1} \mathrm{~F}$

9. $5 p^{3} \mathrm{D}_{2}$

The calculated values of the levels ${ }^{1} \mathrm{D}\left({ }^{3} \mathrm{P}\right){ }^{3} \mathrm{P}_{1,2}$ are, on the average, higher by 1000 than the experimental values of the levels $y{ }^{3} \mathrm{P}_{1,2}$. Such high deviations would be completely inconsistent with all the results obtained thus far. However, the experimental levels $y^{3} \mathrm{P}_{1,2}$ correspond very closely to the calculated values of the levels ${ }^{1} \mathrm{D}\left({ }^{3} \mathrm{P}\right)^{3} \mathrm{D}_{1,2}$ but there is a very large discrepancy between the experimental $g$-factor of 1.32 for $y^{3} \mathrm{P}_{1}$ and the calculated $g$-factor of 0.643 for ${ }^{1} \mathrm{D}\left({ }^{3} \mathrm{P}\right)^{3} \mathrm{D}_{1}$.

Experimental $g$-factors for $\mathrm{Ni}$ I were obtained by Bakker [11], Marvin and Baragar [12], Dijkstra [13], and Lindsley [14]. For many levels 4 different $g$-factors were obtained, usually differing from each other by very little. However, the experimental $g$-factor for $y^{3} \mathrm{P}_{1}$ was obtained only by Lindsley [14]. Furthermore, not only is the value of 1.32 based on one very weak separate line, $b^{3} \mathrm{D}_{2}-y^{3} \mathrm{P}_{1}$, with only one measurement used to determine this value, but, actually "only the difference of the $g$ 's could be determined from the pattern because of overlapping", [14]. Then the average 
$g$-factor of the better known level, here $b^{3} \mathrm{D}_{2}$, was assumed.

Thus, we felt justified in neglecting the $g$-factor of 1.32 and performing the first change above, yielding deviations of only 37 and 64 .

The experimental level $x^{3} \mathrm{D}_{2}$ at 42954 is then assigned to the previously vacant theoretical level ${ }^{1} \mathrm{D}\left({ }^{3} \mathrm{P}\right){ }^{3} \mathrm{~F}_{2}$, yielding a deviation of only -22 . The experimental $g$-factor of 0.840 corresponds to the calculated value of 0.744 .

The experimental level $x^{3} \mathrm{~F}_{4}$ fits very well in height and $g$-factor to the corresponding calculated values of ${ }^{1} \mathrm{D}\left({ }^{3} \mathrm{P}\right)^{3} \mathrm{~F}_{4}$. However, the experimental level $x^{3} \mathrm{~F}_{3}$, whose term designation is questioned by Russell [10], (the question mark is not in the right place in AEL), cannot be assigned to ${ }^{1} \mathrm{D}\left({ }^{3} \mathrm{P}\right)^{3} \mathrm{~F}_{3}$, as the deviation would then be about 900 , which is completely incompatible with the deviations of -22 and -10 obtained for the other two levels assigned to ${ }^{1} \mathrm{D}\left({ }^{3} \mathrm{P}\right)^{3} \mathrm{~F}$. Thus, as indicated by change 3 , the level $w^{3} \mathrm{D}_{3}$ is assigned to ${ }^{1} \mathrm{D}\left({ }^{3} \mathrm{P}\right){ }^{3} \mathrm{~F}_{3}$ with a resulting deviation of only -54 and excellent agreement between the experimental and calculated $g$-factors (1.22 vs 1.189). Then the experimental level $x^{3} \mathrm{~F}_{3}$ is assigned to the vacant level ${ }^{3} \mathrm{~F}\left({ }^{1} \mathrm{P}\right){ }^{3} \mathrm{D}_{3}$, yielding a deviation of only -119 . The experimental $g$-factor of 1.24 compares favorably with the calculated value of 1.317 .

The calculated values of the terms ${ }^{1} \mathrm{D}\left({ }^{1} \mathrm{P}\right)^{1} \mathrm{D}$ and ${ }^{1} \mathrm{D}\left({ }^{1} \mathrm{P}\right){ }^{1} \mathrm{P}$ are 58144 and 58832 , respectively. Thus, the experimental terms $x^{1} \mathrm{D}$ and $y^{1} \mathrm{P}$ cannot be fitted to the theoretical terms with the same designations. As indicated by the changes 4 and 5 , these two levels are assigned to the vacant levels ${ }^{1} \mathrm{D}\left({ }^{3} \mathrm{P}\right)^{3} \mathrm{P}_{1,2}$ (see change 1 ). The resulting deviations are only 18 and 0 , and there is excellent agreement between the experimental and calculated $g$-factors (the experimental values of 1.48 and 1.39 correspond to the calculated values of 1.457 and 1.418 , respectively).

Similarly, since the calculated value of the term ${ }^{1} \mathrm{D}\left({ }^{1} \mathrm{P}\right)^{1} \mathrm{~F}$ is 56358 the experimental term $x^{1} \mathrm{~F}$ is erroneously designated. Russell, [10], observed that $x^{1} \mathrm{~F}$ has combinations with the levels of $a^{3} \mathrm{D}, a^{3} \mathrm{~F}$ and $a^{1} \mathrm{D}$. However, the transition with $a^{1} \mathrm{D}$ is questioned and thus, we felt justified in assigning $x^{1} \mathrm{~F}$ to the only vacant theoretical level with $J$-value of 3 in that range, i.e., ${ }^{3} \mathrm{P}\left({ }^{3} \mathrm{P}\right){ }^{5} \mathrm{D}_{3}$, as indicated by change 6 . The resulting deviation is only 47 .

When the levels $w^{3} \mathrm{~F}_{3}$ and $y^{3} \mathrm{G}_{3}$ were assigned to the theoretical levels with the same term designations, the deviations were -562 and 714 , respectively. When these two levels are interchanged the deviations for $w^{3} \mathrm{~F}_{3}$ and $y^{3} \mathrm{G}_{3}$ are only -19 and 154 , respectively. However, then the experimental values of 0.78 and 1.04 for the $g$-factors do not agree well with the calculated values of 1.059 and 0.784 , respectively. As in the case of $y^{3} \mathrm{P}_{1}$, of the 4 sources of the experimental $g$-factors of $\mathrm{Ni}$, the values for $w^{3} \mathrm{~F}_{3}$ and $y^{3} \mathrm{G}_{3}$ were obtained only by Lindsley, [14]. The $g$-factor of 1.04 is based on two lines, one of which is unresolved, and the $g$-factor of 0.78 is based on only one unresolved line. In all cases, the average $g$-factors for the even levels $\left(a^{3} \mathrm{~F}_{2}\right.$ and $a^{3} \mathrm{~F}_{3}$ ) were assumed in order to obtain the $g$-factor for the odd levels. Thus, as for $y^{3} \mathrm{P}_{1}$, the discrepancies in the $g$-factors were disregarded, and the exchange 7 performed.

For the exchange 8 it should be noted that the eigenfunctions of $5 p^{1} \mathrm{~F}$ and $5 p^{3} \mathrm{~F}_{3}$ are mixed strongly. In the configuration $3 d^{9} 5 p$ the coupling is more likely $J l$ than $L S$ which explains the large mixture of $L S$ components.

The last exchange had already been performed when the configuration $3 d^{9} 5 p$ was considered alone. Since the calculated values of the levels $5 p^{1} \mathrm{D}$ and $5 p^{3} \mathrm{D}_{2}$ are 49003 and 50674, respectively, it is evident that the term designations for the two experimental levels $5 p^{3} \mathrm{D}_{2}$ at 49185 and $5 p^{1} \mathrm{D}$ at 50689 should be interchanged.

The eigenfunctions of the levels ${ }^{3} \mathrm{~F}\left({ }^{3} \mathrm{P}\right) y^{3} \mathrm{D}_{2}$ and ${ }^{3} \mathbf{F}\left({ }^{3} \mathrm{P}\right) y^{3} \mathrm{~F}_{2}$ are so strongly mixed that it is not meaningful to give one particular term designation to each level.

It should be emphasized that as in previous configurations investigated the parameters were first determined - within small ranges of possible fluctuations by those levels inserted whose experimental and theoretical term designations coincided. The other levels, with changed assignments, were only inserted later.

The following table gives the assignments of the undesignated levels:

TABLE 2. Undesignated odd levels of $\mathrm{Ni} \mathrm{I}$

\begin{tabular}{|c|c|c|c|c|}
\hline Level & Assignment & Deviation & $\begin{array}{c}\text { Obs. } \\
\text { g-factor }\end{array}$ & $\begin{array}{l}\text { Calc. } \\
g \text {-factor }\end{array}$ \\
\hline $1_{3}^{\circ}$ & ${ }^{3} \mathrm{P}\left({ }^{3} \mathrm{P}\right){ }^{5} \mathrm{P}_{3}$ & 74 & & 1.633 \\
\hline $22_{2}^{\circ}$ & ${ }^{3} \mathrm{P}\left({ }^{3} \mathrm{P}\right){ }^{5} \mathrm{P}_{2}$ & 26 & & 1.796 \\
\hline $3^{\circ}$ & $\left({ }^{3} \mathrm{P}\left({ }^{3} \mathrm{P}\right)^{5} \mathrm{D}_{4}\right)$ & $(336)$ & & (1.294) \\
\hline $4_{2}^{\circ}$ & ${ }^{3} \mathrm{P}\left({ }^{3} \mathrm{P}\right){ }^{5} \mathrm{~S}_{2}$ & -188 & & 1.874 \\
\hline $5_{2,1}^{\circ}$ & ${ }^{3} \mathrm{P}\left({ }^{3} \mathrm{P}\right){ }^{1} \mathrm{P}_{1}$ & 91 & & 1.063 \\
\hline $6_{3}^{\circ}$ & ${ }^{3} \mathrm{P}\left({ }^{3} \mathrm{P}\right){ }^{1} \mathrm{D}_{2}$ & -104 & $\ldots \ldots$ & 1.030 \\
\hline
\end{tabular}

As explained before, the level $3^{\circ}$ was not included in the least-squares, and thus entries pertaining to it are given in parentheses.

For the level $6^{\circ}$, Russell [10], gives 7 combinations with the levels of the 4 even terms $a^{3} \mathrm{P}, a^{1} \mathrm{D}, a^{3} \mathrm{~F}$, and $a^{3} \mathrm{D}$. Thus, it is evident that $6^{\circ}$ is a valid level, but there is no corresponding experimental level with $J$-value of 3 to which it can be assigned. An examination of the identified lines of $\mathrm{Ni}$ I, [10], reveals that the only transition of the level $6^{\circ}$ with an even level of $J$-value 4 is the weak line $a^{3} \mathrm{~F}_{4}-6^{\circ}$ at 49032 . However, this line was measured by Shenstone in the spectrum of Ni II, [15]. Then neglecting the above transition, the level $6^{\circ}$ can be assigned to ${ }^{3} \mathrm{P}\left({ }^{3} \mathrm{P}\right)^{1} \mathrm{D}$, as indicated above.

Below 54000, (the limit of the experimental data available), there are 10 theoretical levels with no corresponding experimental levels. The lowest of these is the level ${ }^{3} \mathrm{P}\left({ }^{3} \mathrm{P}\right){ }^{5} \mathrm{P}_{1}$ at 40695 .

As mentioned previously, whenever there is more than one experimental source for the g-factors, the 
agreement is usually very good between the various values obtained. The only exceptions are the $g$-factors of the levels $y^{3} \mathrm{~F}_{2}$ and $y^{3} \mathrm{D}_{2}$, which were measured by Lindsley, [14], and Marvin and Baragar, [12]. Lindsley's value of 0.973 for $y^{3} \mathrm{~F}_{2}$ is based on 6 separate lines with 14 measurements taken, and his value of 0.859 for $y^{3} \mathrm{D}_{2}$ is also based on 6 separate lines with 19 measurements taken. In only one of these 12 lines is the $g$ factor for the even level assumed. The experimental values of 0.79 and 1.19 obtained for the $g$-factors of $y^{3} \mathrm{~F}_{2}$ and $y^{3} \mathrm{D}_{2}$ by Marvin and Baragar are based on only two lines in each case. Although for these two levels the $g$-factors of Marvin and Baragar are quoted in AEL, it seems evident that Lindsley's values are more reliable and should be adopted. This assumption is verified by the calculated $g$-factors obtained in the present investigation. For the theoretical levels ${ }^{3} \mathrm{~F}\left({ }^{3} \mathrm{P}\right)^{3} \mathrm{~F}_{2}$ and ${ }^{3} \mathrm{~F}\left({ }^{3} \mathrm{P}\right)^{3} \mathrm{D}_{2}$, the $g$-factors of 0.903 and 0.929 , respectively, are obtained to which Lindsley's values fit much better than those of Marvin and Baragar.

With the exception of the $g$-factors for $y^{3} \mathrm{P}_{1}, w^{3} \mathrm{~F}_{3}$ and $y^{3} \mathrm{G}_{3}$, discussed previously, the agreement between the experimental and calculated $g$-factors is very good.

The calculated values, percentage compositions and $g$-factors of all the 114 predicted levels (50 terms) of $3 d^{9} 4 p+3 d^{8} 4 s 4 p+3 d^{9} 5 p$ are given in table $\mathrm{A}$.

It is interesting to note that the rms error of 131 for the configurations $(3 d+4 s)^{9} 4 p$ is lower than the present value of 147. The difference between the rms deviations is not so large, since for $(3 d+4 s)^{9} 4 p$ there are 17 free parameters for 71 levels yielding an $\mathrm{rms}$ deviation of 114 , whereas for $3 d^{9} 4 p+3 d^{8} 4 s 4 p+3 d^{9} 5 p$, there are 25 free parameters for 83 levels giving an rms deviation of only 122 .

Finally, the rms error of 147 obtained here should be compared with the rms errors of 173 for $3 d^{9} 4 p$
$+3 d^{8} 4 s 4 p$ and 139 for $3 d^{9} 5 p$. Since the configuration $3 d^{9} 5 p$ lies within the range of the observed levels of $3 d^{8} 4 s 4 p$ a greater improvement may have been expected. However, from table $\mathrm{A}$ it is apparent that although the eigenfunctions of the levels of $3 d^{9} 4 p$ are mixed considerably, the mixing is mostly among eigenfunctions belonging to $3 d^{9} 5 p$. Only the eigenfunctions of two levels from $3 d^{8} 4 s 4 p$ comprise contributions of more than 15 percent belonging to $3 d^{9} 5 p$. These are the levels ${ }^{1} \mathrm{G}\left({ }^{3} \mathrm{P}\right)^{3} \mathrm{~F}_{2,3}$. Although for $(3 d+4 s)^{9} 4 p$ the mean deviation for the levels of ${ }^{1} \mathrm{G}\left({ }^{3} \mathrm{P}\right){ }^{3} \mathrm{~F}$ is only 109 , in the present case the mean deviation is reduced to 13 .

\section{Appendix}

\section{Table A. Observed and Calculated Levels and g-Factors}

In the column "Name" the calculated designation of the term is given. The terms of $d^{8} s p$ are denoted by $d^{8} v_{1} S_{1} L_{1}\left(s p^{1,3} \mathbf{P}\right) S L$.

The entries in the columns " $J$ ", "Obs. Level $\left(\mathrm{cm}^{-1}\right)$ ", "Calc. Level $\left(\mathrm{cm}^{-1}\right)$ ", "Obs. g-Factor" and "Calc. g-Factor" are self-evident. In the column "Percentage" for each calculated level either the three highest contributions or all those contributions exceeding five percent are given.

Whenever the experimental and calculated term designations differ, the experimental designation is entered in the column "AEL", with the notation of C. E. Moore, [1]. In many instances the exchanges involve complete terms rather than isolated levels. Unless specified otherwise, the entries in the column "AEL" pertain to exchanges in terms.

The column "O-C" gives the difference between the observed and calculated values of the levels.

The entries are in increasing energy of the calculated values.

TABLE A. Observed and calculated levels of $\mathrm{Ni}$ I $3 d^{9} 4 p+3 d^{8} 4 s 4 p+3 d^{9} 5 p$

\begin{tabular}{|c|c|c|c|c|c|c|c|c|c|}
\hline \multirow{2}{*}{ Name } & \multirow{2}{*}{$J$} & \multirow{2}{*}{ Percentage } & \multicolumn{2}{|l|}{ AEL } & \multirow{2}{*}{$\begin{array}{l}\text { Obs. } \\
\text { Level } \\
\left(\mathrm{cm}^{-1}\right)\end{array}$} & \multirow{2}{*}{$\begin{array}{l}\text { Calc. } \\
\text { Level } \\
\left(\mathrm{cm}^{-1}\right)\end{array}$} & \multirow{2}{*}{$\mathrm{O}-\mathrm{C}$} & \multirow{2}{*}{$\begin{array}{l}\text { Obs. } \\
g \text {-Factor }\end{array}$} & \multirow{2}{*}{$\begin{array}{c}\text { Calc. } \\
g \text {-Factor }\end{array}$} \\
\hline & & & Config. & Desig. & & & & & \\
\hline${ }^{3} \mathrm{~F}\left({ }^{3} \mathrm{P}\right){ }^{5} \mathrm{D}$ & $\begin{array}{l}0 \\
1 \\
2 \\
3 \\
4\end{array}$ & $\begin{array}{l}96 \\
95 \\
94 \\
94 \\
96\end{array}$ & $3 d^{8} 4 s\left(a^{4} \mathrm{~F}\right) 4 p$ & $z^{5} \mathrm{D}$ & $\begin{array}{l}28213 \\
27944 \\
27415 \\
26666 \\
25754\end{array}$ & $\begin{array}{l}28241 \\
28008 \\
27551 \\
26906 \\
26119\end{array}$ & $\begin{array}{r}-28 \\
-64 \\
-136 \\
-240 \\
-365\end{array}$ & $\begin{array}{l}1.486 \\
1.49 \\
1.50 \\
1.51\end{array}$ & $\begin{array}{l}1.486 \\
1.488 \\
1.492 \\
1.497\end{array}$ \\
\hline${ }^{3} \mathrm{~F}\left({ }^{3} \mathrm{P}\right){ }^{5} \mathrm{G}$ & $\begin{array}{l}2 \\
3 \\
4 \\
5 \\
6\end{array}$ & $\begin{array}{ll}90+6^{3} \mathrm{~F}\left({ }^{3} \mathrm{P}\right)^{5} \mathrm{~F} & 96 \\
87+8^{3} \mathrm{~F}\left({ }^{3} \mathrm{P}\right)^{5} \mathrm{~F} & \\
88+10^{3} \mathrm{~F}\left({ }^{3} \mathrm{P}\right)^{5} \mathrm{~F} & \\
& 100\end{array}$ & $3 d^{8} 4 s\left(a^{4} \mathrm{~F}\right) 4 p$ & $z^{5} \mathrm{G}$ & $\begin{array}{l}29013 \\
28578 \\
28068 \\
27580 \\
27261\end{array}$ & $\begin{array}{l}28856 \\
28473 \\
28015 \\
27543 \\
27151\end{array}$ & $\begin{array}{r}157 \\
105 \\
53 \\
37 \\
110\end{array}$ & $\begin{array}{l}0.364 \\
0.945 \\
1.171 \\
1.28 \\
1.32\end{array}$ & $\begin{array}{l}0.359 \\
0.938 \\
1.165 \\
1.277 \\
1.333\end{array}$ \\
\hline${ }^{3} \mathrm{~F}\left({ }^{3} \mathrm{P}\right)^{5} \mathrm{~F}$ & $\begin{array}{l}1 \\
2 \\
3 \\
4 \\
5\end{array}$ & \begin{tabular}{l}
\multicolumn{1}{c}{97} \\
$72+9\left({ }^{2} \mathrm{D}\right) 4 p^{3} \mathrm{D}+7\left({ }^{2} \mathrm{D}\right) 4 p^{1} \mathrm{D}$ \\
$84+5^{3} \mathrm{~F}\left({ }^{3} \mathrm{P}\right)^{5} \mathrm{G}$ \\
$76+9\left({ }^{2} \mathrm{D}\right) 4 p^{3} \mathrm{~F}+8^{3} \mathrm{~F}\left({ }^{3} \mathrm{P}\right)^{5} \mathrm{G}$ \\
$90+8^{3} \mathrm{~F}\left({ }^{3} \mathrm{P}\right)^{5} \mathrm{G}$
\end{tabular} & $3 d^{8} 4 s\left(a^{4} \mathrm{~F}\right) 4 p$ & $z^{5} \mathrm{~F}$ & $\begin{array}{l}30392 \\
30163 \\
29833 \\
29084 \\
28542\end{array}$ & $\begin{array}{l}30231 \\
30030 \\
29658 \\
29094 \\
28490\end{array}$ & $\begin{array}{r}161 \\
133 \\
175 \\
-10 \\
52\end{array}$ & $\begin{array}{l}0.006 \\
0.985 \\
1.208 \\
1.288 \\
1.38\end{array}$ & $\begin{array}{l}0.020 \\
1.012 \\
1.219 \\
1.317 \\
1.386\end{array}$ \\
\hline
\end{tabular}


TABLE A. Observed and calculated levels of $\mathrm{Ni}$ I $3 d^{9} 4 p+3 d^{8} 4 s 4 p+3 d^{9} 5 p-$ Continued

\begin{tabular}{|c|c|c|c|c|c|c|c|c|c|}
\hline \multirow{2}{*}{ Name } & \multirow{2}{*}{$J$} & \multirow{2}{*}{ Percentage } & \multicolumn{2}{|l|}{ AEL } & \multirow{2}{*}{$\begin{array}{l}\text { Obs. } \\
\text { Level } \\
\left(\mathrm{cm}^{-1}\right)\end{array}$} & \multirow{2}{*}{$\begin{array}{l}\text { Calc. } \\
\text { Level } \\
\left(\mathrm{cm}^{-1}\right)\end{array}$} & \multirow{2}{*}{$\mathrm{O}-\mathrm{C}$} & \multirow{2}{*}{$\begin{array}{c}\text { Obs. } \\
g \text {-Factor }\end{array}$} & \multirow{2}{*}{$\begin{array}{c}\text { Calc. } \\
g \text {-Factor }\end{array}$} \\
\hline & & & Config. & Desig. & & & & & \\
\hline \multirow[t]{3}{*}{$\left({ }^{2} \mathrm{D}\right) 4 p^{3} \mathrm{P}$} & 0 & 96 & & & 30192 & 30183 & 9 & & \\
\hline & 1 & $87+5\left({ }^{2} \mathrm{D}\right) 4 p^{3} \mathrm{D}$ & & & 29501 & 29498 & 3 & 1.426 & 1.420 \\
\hline & 2 & $91+4\left({ }^{2} \mathrm{D}\right) 4 p^{3} \mathrm{D}$ & & & 28569 & 28590 & -21 & 1.485 & 1.481 \\
\hline \multirow[t]{3}{*}{$\left({ }^{2} \mathrm{D}\right) 4 p{ }^{3} \mathrm{~F}$} & 2 & $72+10^{3} \mathrm{~F}\left({ }^{3} \mathrm{P}\right){ }^{3} \mathrm{~F}+6\left({ }^{2} \mathrm{D}\right) 4 p^{3} \mathrm{D}$ & & & 30619 & 30655 & -36 & 0.740 & 0.742 \\
\hline & 3 & $48+27\left({ }^{2} \mathrm{D}\right) 4 p^{1} \mathrm{~F}+8\left({ }^{2} \mathrm{D}\right) 4 p^{3} \mathrm{D}$ & & & 29321 & 29323 & -2 & 1.086 & 1.087 \\
\hline & 4 & $79+12^{3} \mathrm{~F}\left({ }^{3} \mathrm{P}\right)^{5} \mathrm{~F}+6^{3} \mathrm{~F}\left({ }^{3} \mathrm{P}\right)^{3} \mathrm{~F}$ & & & 29481 & 29419 & 62 & 1.287 & 1.263 \\
\hline \multirow[t]{3}{*}{$\left({ }^{2} \mathrm{D}\right) 4 p{ }^{3} \mathrm{D}$} & 1 & $59+30^{3} \mathrm{~F}\left({ }^{3} \mathrm{P}\right)^{3} \mathrm{D}$ & & & 30913 & 30919 & -6 & 0.552 & 0.564 \\
\hline & 2 & $28+22^{3} \mathrm{~F}\left({ }^{3} \mathrm{P}\right){ }^{5} \mathrm{~F}+17\left({ }^{2} \mathrm{D}\right) 4 p^{1} \mathrm{D}$ & & & 29888 & 29893 & -5 & 1.044 & 1.021 \\
\hline & 3 & $59+24{ }^{3} \mathrm{~F}\left({ }^{3} \mathrm{P}\right){ }^{3} \mathrm{D}+11\left({ }^{2} \mathrm{D}\right) 4 p^{1} \mathrm{~F}$ & & & 29669 & 29760 & -91 & 1.300 & 1.290 \\
\hline$\left({ }^{2} \mathrm{D}\right) 4 p{ }^{1} \mathrm{~F}$ & 3 & $52+34\left(\left(^{2} \mathrm{D}\right) 4 \mathrm{p}^{3} \mathrm{~F}\right.$ & & & 31031 & 31021 & 10 & 1.048 & 1.049 \\
\hline$\left({ }^{2} \mathrm{D}\right) 4 p^{1} \mathrm{D}$ & 2 & $61+17\left({ }^{2} \mathrm{D}\right) 4 p^{3} \mathrm{D}+12^{3} \mathrm{~F}\left({ }^{3} \mathrm{P}\right)^{3} \mathrm{D}$ & & & 31442 & 31418 & 24 & 1.060 & 1.060 \\
\hline \multirow[t]{3}{*}{${ }^{3} \mathrm{~F}\left({ }^{3} \mathrm{P}\right)^{3} \mathrm{G}$} & 3 & 95 & $3 d^{8} 4 s\left(a^{2} \mathrm{~F}\right) 4 p$ & $z^{3} \mathrm{G}$ & 31786 & 31765 & 21 & 0.761 & 0.763 \\
\hline & 4 & 91 & & & 30980 & 31061 & -81 & 1.052 & 1.049 \\
\hline & 5 & 96 & & & 30923 & 30917 & 6 & 1.21 & 1.203 \\
\hline$\left({ }^{2} \mathrm{D}\right) 4 \mathrm{p}^{1} \mathrm{P}$ & 1 & 95 & & & 32982 & 32983 & -1 & 1.005 & 1.008 \\
\hline \multirow[t]{3}{*}{${ }^{3} \mathrm{~F}\left({ }^{3} \mathrm{P}\right)^{3} \mathrm{~F}$} & 2 & $49+35^{3} \mathrm{~F}\left({ }^{3} \mathrm{P}\right)^{3} \mathrm{D}$ & $3 d^{8} 4 s\left(a^{2} \mathrm{~F}\right) 4 p$ & $y^{3} \mathrm{D}$ & 34163 & 34096 & 67 & 0.859 & 0.903 \\
\hline & 3 & $43+29^{3} \mathrm{~F}\left({ }^{3} \mathrm{P}\right)^{3} \mathrm{D}$ & $3 d^{8} 4 s\left(a^{2} \mathrm{~F}\right) 4 p$ & $y^{3} \mathrm{~F}$ & 33112 & 33197 & -85 & 1.193 & 1.181 \\
\hline & 4 & 86 & & & 32973 & 32994 & -21 & 1.22 & 1.216 \\
\hline${ }^{3} \mathrm{~F}\left({ }^{3} \mathrm{P}\right){ }^{1} \mathrm{G}$ & 4 & $72+13^{3} \mathrm{~F}\left({ }^{3} \mathrm{P}\right)^{3} \mathrm{G}+12^{3} \mathrm{~F}\left({ }^{3} \mathrm{P}\right)^{3} \mathrm{~F}$ & $3 d^{8} 4 s\left(a^{2} \mathrm{~F}\right) 4 p$ & $z^{1} \mathrm{G}$ & 33590 & 33619 & -29 & 1.035 & 1.043 \\
\hline \multirow[t]{3}{*}{${ }^{3} \mathrm{~F}\left({ }^{3} \mathrm{P}\right){ }^{3} \mathrm{D}$} & 1 & $69+27\left({ }^{2} \mathrm{D}\right) 4 \mathrm{p}^{3} \mathrm{D}$ & $3 d^{8} 4 s\left(a^{2} \mathrm{~F}\right) 4 p$ & $y^{3} \mathrm{D}$ & 34409 & 34410 & -1 & 0.511 & 0.507 \\
\hline & 2 & $31+39^{3} \mathrm{~F}\left({ }^{3} \mathrm{P}\right)^{3} \mathrm{~F}+17\left({ }^{2} \mathrm{D}\right) 4 \mathrm{p}^{3} \mathrm{D}$ & $3 d^{8} 4 s\left(a^{2} \mathrm{~F}\right) 4 p$ & $y^{3} \mathrm{~F}$ & 33611 & 33622 & -11 & 0.973 & 0.929 \\
\hline & 3 & $45+32^{3} \mathrm{~F}\left({ }^{3} \mathrm{P}\right)^{3} \mathrm{~F}$ & $3 d^{8} 4 s\left(a^{2} \mathrm{~F}\right) 4 p$ & $y^{3} \mathrm{D}$ & 33501 & 33511 & -10 & 1.198 & 1.219 \\
\hline${ }^{3} \mathrm{~F}\left({ }^{3} \mathrm{P}\right){ }^{1} \mathrm{~F}$ & 3 & $84+10^{3} \mathrm{~F}\left({ }^{3} \mathrm{P}\right)^{3} \mathrm{~F}$ & $3 d^{8} 4 s\left(a^{2} \mathrm{~F}\right) 4 p$ & $y^{\mathrm{i}} \mathrm{F}$ & 35639 & 35723 & -84 & 1.013 & 1.014 \\
\hline${ }^{3} \mathrm{~F}\left({ }^{3} \mathrm{P}\right){ }^{1} \mathrm{D}$ & 2 & $82+8\left({ }^{2} \mathrm{D}\right) 4 \mathrm{p}^{1} \mathrm{D}$ & $3 d^{8} 4 s\left(a^{2} \mathrm{~F}\right) 4 p$ & $y^{1} \mathrm{D}$ & 36601 & 36480 & 121 & 1.013 & 1.012 \\
\hline \multirow[t]{3}{*}{${ }^{3} \mathrm{P}\left({ }^{3} \mathrm{P}\right)^{5} \mathrm{P}$} & 1 & 96 & & & & 40695 & & & 2.456 \\
\hline & 2 & 92 & & $2^{\circ}$ & 40484 & 40458 & 26 & & 1.796 \\
\hline & 3 & $90+8^{1} \mathrm{D}\left({ }^{3} \mathrm{P}\right)^{3} \mathrm{D}$ & & $1^{\circ}$ & 40361 & 40287 & 74 & & 1.633 \\
\hline \multirow[t]{3}{*}{${ }^{1} \mathrm{D}\left({ }^{3} \mathrm{P}\right)^{3} \mathrm{D}$} & 1 & $75+10^{3} \mathrm{~F}\left({ }^{3} \mathrm{P}\right)^{3} \mathrm{D}$ & $3 d^{8} 4 s\left(b^{2} \mathrm{D}\right) 4 p$ & $y^{3} \mathrm{P}$ & 42656 & 42619 & 37 & (1.32) & 0.643 \\
\hline & 2 & $68+12^{3} \mathrm{~F}\left({ }^{3} \mathrm{P}\right)^{3} \mathrm{D}$ & & & 42654 & 42590 & 64 & & 1.202 \\
\hline & 3 & $41+39^{3} \mathrm{~F}\left({ }^{3} \mathrm{P}\right)^{3} \mathrm{D}$ & $3 d^{8} 4 s\left(b^{2} \mathrm{D}\right) 4 p$ & $x^{3} \mathrm{D}$ & 42621 & 42418 & 203 & & 1.354 \\
\hline \multirow[t]{3}{*}{${ }^{1} \mathrm{D}\left({ }^{3} \mathrm{P}\right)^{3} \mathrm{~F}$} & 2 & $80+4{ }^{3} \mathrm{P}\left({ }^{3} \mathrm{P}\right)^{5} \mathrm{D}$ & $3 d^{8} 4 s\left(b^{2} \mathrm{D}\right) 4 p$ & $x^{3} \mathrm{D}$ & 42954 & 42976 & -22 & 0.840 & 0.744 \\
\hline & 3 & $66+20^{3} \mathrm{P}\left({ }^{3} \mathrm{P}\right)^{5} \mathrm{D}$ & $3 d^{8} 4 s\left(a^{4} \mathrm{~F}\right) 4 p$ & $w^{3} \mathrm{D}$ & 42768 & 42822 & -54 & 1.22 & 1.189 \\
\hline & 4 & $53+39^{3} \mathrm{P}\left({ }^{3} \mathrm{P}\right)^{5} \mathrm{D}$ & $3 d^{8} 4 s\left(b^{2} \mathrm{D}\right) 4 p$ & $x^{3} \mathrm{~F}$ & 42585 & 42595 & -10 & 1.35 & 1.349 \\
\hline \multirow[t]{3}{*}{$\left.{ }^{1} \mathrm{D}\left({ }^{3} \mathrm{P}\right)\right)^{3} \mathrm{P}$} & 0 & $62+32^{3} \mathrm{P}\left({ }^{3} \mathrm{P}\right)^{3} \mathrm{P}$ & & & & 43079 & & & \\
\hline & 1 & $59+23^{3} \mathrm{P}\left({ }^{3} \mathrm{P}\right)^{3} \mathrm{P}+8^{1} \mathrm{D}\left({ }^{3} \mathrm{P}\right)^{3} \mathrm{D}$ & $3 d^{8} 4 s\left(b^{2} \mathrm{D}\right) 4 p$ & $y^{1} \mathrm{P}$ & 43464 & 43464 & 0 & 1.39 & 1.418 \\
\hline & 2 & $44+27^{3} \mathrm{P}\left({ }^{3} \mathrm{P}\right)^{5} \mathrm{D}+12^{3} \mathrm{P}\left({ }^{3} \mathrm{P}\right)^{3} \mathrm{P}$ & $3 d^{8} 4 s\left(b^{2} \mathrm{D}\right) 4 p$ & $x^{1} \mathrm{D}$ & 43933 & 43915 & 18 & 1.48 & 1.457 \\
\hline
\end{tabular}


TABLE A. Observed and calculated levels of $\mathrm{Ni}$ I $3 d^{9} 4 p+3 d^{8} 4 s 4 p+3 d^{9} 5 p-$ Continued

\begin{tabular}{|c|c|c|c|c|c|c|c|c|c|}
\hline \multirow{2}{*}{ Name } & \multirow{2}{*}{$J$} & \multirow{2}{*}{ Percentage } & \multicolumn{2}{|l|}{ AEL } & \multirow{2}{*}{$\begin{array}{l}\text { Obs. } \\
\text { Level } \\
\left(\mathrm{cm}^{-1}\right)\end{array}$} & \multirow{2}{*}{$\begin{array}{l}\text { Calc. } \\
\text { Level } \\
\left(\mathrm{cm}^{-1}\right)\end{array}$} & \multirow{2}{*}{$\mathrm{O}-\mathrm{C}$} & \multirow{2}{*}{$\begin{array}{l}\text { Obs. } \\
g \text {-Factor }\end{array}$} & \multirow{2}{*}{$\begin{array}{c}\text { Calc. } \\
\text { g-Factor }\end{array}$} \\
\hline & & & Config. & Desig. & & & & & \\
\hline \multirow[t]{5}{*}{${ }^{3} \mathrm{P}\left({ }^{3} \mathrm{P}\right){ }^{5} \mathrm{D}$} & 0 & 91 & & & & 44134 & & & \\
\hline & 1 & 89 & & & & 44094 & & & 1.485 \\
\hline & 2 & $56+27^{1} \mathrm{D}\left({ }^{3} \mathrm{P}\right)^{3} \mathrm{P}$ & & & & 44061 & & & 1.461 \\
\hline & 3 & $58+17^{1} \mathrm{D}\left({ }^{3} \mathrm{P}\right)^{3} \mathrm{D}+11^{1} \mathrm{D}\left({ }^{3} \mathrm{P}\right)^{3} \mathrm{~F}$ & $3 d^{8} 4 s\left(b^{2} \mathrm{D}\right) 4 p$ & $x^{1} \mathrm{~F}$ & 44206 & 44159 & 47 & & 1.401 \\
\hline & 4 & $34+30^{3} \mathrm{~F}\left({ }^{1} \mathrm{P}\right)^{3} \mathrm{~F}+21^{3} \mathrm{~F}\left({ }^{1} \mathrm{P}\right)^{3} \mathrm{G}$ & & & & 44000 & & & 1.294 \\
\hline \multirow[t]{3}{*}{${ }^{3} \mathrm{~F}\left({ }^{1} \mathrm{P}\right)^{3} \mathrm{G}$} & 3 & 91 & $3 d^{8} 4 s\left(a^{4} \mathrm{~F}\right) 4 p$ & $w^{3} \mathrm{~F}$ & 44565 & 44411 & 154 & $(1.04)$ & 0.784 \\
\hline & 4 & $72+24^{3} \mathrm{~F}\left({ }^{1} \mathrm{P}\right)^{3} \mathrm{~F}$ & $3 d^{8} 4 s\left(a^{4} \mathrm{~F}\right) 4 p$ & $y^{3} \mathrm{G}$ & 44315 & 44567 & -252 & 1.18 & 1.289 \\
\hline & 5 & 100 & & & 43090 & 42572 & 518 & 1.23 & 1.200 \\
\hline \multirow[t]{3}{*}{${ }^{3} \mathrm{~F}\left({ }^{1} \mathrm{P}\right){ }^{3} \mathrm{D}$} & 1 & $67+11^{3} \mathrm{P}\left({ }^{3} \mathrm{P}\right)^{3} \mathrm{D}$ & $3 d^{8} 4 s\left(a^{4} \mathrm{~F}\right) 4 p$ & $w^{3} \mathrm{D}$ & 45122 & 45008 & 114 & 0.57 & 0.471 \\
\hline & 2 & $56+15^{1} \mathrm{D}\left({ }^{3} \mathrm{P}\right)^{3} \mathrm{D}$ & & & 44475 & 44479 & -4 & 1.16 & 1.172 \\
\hline & 3 & $34+29^{1} \mathrm{D}\left({ }^{3} \mathrm{P}\right)^{3} \mathrm{D}+16^{3} \mathrm{P}\left({ }^{3} \mathrm{P}\right)^{5} \mathrm{D}$ & $3 d^{8} 4 s\left(b^{2} \mathrm{D}\right) 4 p$ & $x^{3} \mathrm{~F}$ & 43655 & 43774 & -119 & 1.24 & 1.317 \\
\hline \multirow[t]{3}{*}{${ }^{3} \mathrm{~F}\left({ }^{1} \mathrm{P}\right)^{3} \mathrm{~F}$} & 2 & 86 & $3 d^{8} 4 s\left(a^{4} \mathrm{~F}\right) 4 p$ & $w^{3} \mathrm{~F}$ & 45419 & 45902 & -483 & 0.68 & 0.668 \\
\hline & 3 & 77 & $3 d^{8} 4 s\left(a^{4} \mathrm{~F}\right) 4 p$ & $y^{3} \mathrm{G}$ & 45281 & 45300 & -19 & $(0.78)$ & 1.059 \\
\hline & 4 & $36+30^{1} \mathrm{D}\left({ }^{3} \mathrm{P}\right)^{3} \mathrm{~F}+22^{3} \mathrm{P}\left({ }^{3} \mathrm{P}\right)^{5} \mathrm{D}$ & $3 d^{8} 4 s\left(a^{4} \mathrm{~F}\right) 4 p$ & $w^{3} \mathrm{~F}$ & 43259 & 43501 & -242 & 1.25 & 1.112 \\
\hline \multirow[t]{3}{*}{${ }^{3} \mathrm{P}\left({ }^{3} \mathrm{P}\right)^{3} \mathrm{P}$} & 0 & $63+30^{1} \mathrm{D}\left({ }^{3} \mathrm{P}\right)^{3} \mathrm{P}$ & $3 d^{8} 4 s\left(a^{4} \mathrm{P}\right) 4 p$ & $x^{3} \mathrm{P}$ & $47687 ?$ & 47660 & 27 & & \\
\hline & 1 & $47+19^{3} \mathrm{P}\left({ }^{3} \mathrm{P}\right)^{3} \mathrm{D}+17^{1} \mathrm{D}\left({ }^{3} \mathrm{P}\right)^{3} \mathrm{P}$ & & & 47208 & 47254 & -46 & & 1.203 \\
\hline & 2 & $59+18^{3} \mathrm{P}\left({ }^{3} \mathrm{P}\right)^{5} \mathrm{~S}$ & & & 46523 & 46609 & -86 & & 1.573 \\
\hline \multirow[t]{3}{*}{${ }^{3} \mathbf{P}\left({ }^{3} \mathrm{P}\right)^{3} \mathrm{D}$} & 1 & $66+14^{3} \mathrm{P}\left({ }^{3} \mathrm{P}\right)^{3} \mathrm{P}$ & $3 d^{8} 4 s\left(a^{4} \mathrm{P}\right) 4 p$ & $v^{3} \mathrm{D}$ & 47425 & 47448 & -23 & 0.726 & 0.727 \\
\hline & 2 & 81 & & & 47139 & 47209 & -70 & 1.209 & 1.170 \\
\hline & 3 & 90 & & & 47030 & 47052 & -22 & 1.331 & 1.323 \\
\hline${ }^{3} \mathrm{P}\left({ }^{3} \mathrm{P}\right){ }^{5} \mathrm{~S}$ & 2 & $76+9^{3} \mathrm{P}\left({ }^{3} \mathrm{P}\right){ }^{3} \mathrm{P}+8^{1} \mathrm{D}\left({ }^{3} \mathrm{P}\right)^{3} \mathrm{P}$ & & $4^{\circ}$ & 47329 & 47517 & -188 & & 1.874 \\
\hline$\left({ }^{2} \mathrm{D}\right) 5 p^{1} \mathrm{~F}$ & 3 & $56+35\left({ }^{2} \mathrm{D}\right) 5 p^{3} \mathrm{~F}$ & $3 d^{9}\left(a^{2} \mathrm{D}\right) 5 p$ & $v^{3} \mathrm{~F}$ & 48672 & 48677 & -5 & & 1.052 \\
\hline${ }^{3} \mathrm{P}\left({ }^{3} \mathrm{P}\right){ }^{1} \mathrm{P}$ & 1 & $83+6\left({ }^{2} \mathrm{D}\right) 5 p^{1} \mathrm{P}$ & & $5^{\circ}$ & 48818 & 48727 & 91 & & 1.063 \\
\hline$\left({ }^{2} \mathrm{D}\right) 5 p^{1} \mathrm{D}$ & 2 & $47+17\left({ }^{2} \mathrm{D}\right) 5 p^{3} \mathrm{P}+12^{3} \mathrm{P}\left({ }^{3} \mathrm{P}\right){ }^{1} \mathrm{D}$ & $3 d^{9}\left(a^{2} \mathrm{D}\right) 5 p$ & $u^{3} \mathrm{D}$ & 49185 & 49003 & 182 & & 1.123 \\
\hline${ }^{3} \mathrm{P}\left({ }^{3} \mathrm{P}\right){ }^{1} \mathrm{D}$ & 2 & $75+11\left({ }^{2} \mathrm{D}\right) 5 p{ }^{1} \mathrm{D}$ & & $6^{\circ}$ & 49033 & 49137 & -104 & & 1.030 \\
\hline \multirow[t]{3}{*}{$\left({ }^{2} \mathrm{D}\right) 5 p^{3} \mathrm{P}$} & 0 & $91+8^{3} \mathrm{P}\left({ }^{3} \mathrm{P}\right)^{3} \mathrm{P}$ & & & 50139 & 50159 & -20 & & \\
\hline & 1 & $62+22\left({ }^{2} \mathrm{D}\right) 5 p^{1} \mathrm{P}+7{ }^{3} \mathrm{P}\left({ }^{3} \mathrm{P}\right)^{3} \mathrm{P}$ & & & 49403 & 49238 & 165 & & 1.374 \\
\hline & 2 & $65+19\left({ }^{2} \mathrm{D}\right) 5 p^{1} \mathrm{D}+8{ }^{3} \mathrm{P}\left({ }^{3} \mathrm{P}\right){ }^{3} \mathrm{P}$ & & & 48735 & 48704 & 31 & & 1.403 \\
\hline \multirow[t]{3}{*}{${ }^{1} \mathrm{G}\left({ }^{3} \mathrm{P}\right)^{3} \mathrm{H}$} & 4 & 100 & & & & 49553 & & & 0.800 \\
\hline & 5 & 100 & & & & 49653 & & & 1.034 \\
\hline & 6 & 100 & & & & 49778 & & & 1.167 \\
\hline \multirow[t]{3}{*}{$\left({ }^{2} \mathrm{D}\right) 5 p^{3} \mathrm{~F}$} & 2 & $57+30^{1} \mathrm{G}\left({ }^{3} \mathrm{P}\right)^{3} \mathrm{~F}$ & & & . 50039 & 49937 & 102 & & 0.662 \\
\hline & 3 & $23+24\left({ }^{2} \mathrm{D}\right) 5 p^{3} \mathrm{D}+24\left({ }^{2} \mathrm{D}\right) 5 p^{1} \mathrm{~F}$ & $3 d^{9}\left(a^{2} \mathrm{D}\right) 5 p$ & $w^{1} \mathrm{~F}$ & 50143 & 50074 & 69 & & 1.138 \\
\hline & 4 & $84+13^{1} \mathrm{G}\left({ }^{3} \mathrm{P}\right)^{3} \mathrm{~F}$ & & & 48715 & 48792 & -77 & & 1.251 \\
\hline${ }^{3} \mathrm{P}\left({ }^{3} \mathrm{P}\right)^{3} \mathrm{~S}$ & 1 & 98 & & & & 49928 & & & 1.986 \\
\hline \multirow[t]{3}{*}{$\left({ }^{2} \mathrm{D}\right) 5 p^{3} \mathrm{D}$} & 1 & $80+10^{3} \mathrm{~F}\left({ }^{1} \mathrm{P}\right)^{3} \mathrm{D}$ & & & 50851 & 50929 & -78 & & 0.508 \\
\hline & 2 & $69+11\left({ }^{2} \mathrm{D}\right) 5 p^{1} \mathrm{D}+11{ }^{3} \mathrm{~F}\left({ }^{1} \mathrm{P}\right)^{3} \mathrm{D}$ & $3 d^{9}\left(a^{2} \mathrm{D}\right) 5 p$ & $w^{1} \mathrm{D}$ & 50689 & 50674 & 15 & & 1.130 \\
\hline & 3 & $59+14\left({ }^{2} \mathrm{D}\right) 5 p{ }^{1} \mathrm{~F}+11\left({ }^{2} \mathrm{D}\right) 5 p^{3} \mathrm{~F}$ & & & 49328 & 49423 & -95 & & 1.223 \\
\hline$\left({ }^{2} \mathrm{D}\right) 5 p{ }^{1} \mathrm{P}$ & 1 & $64+26\left({ }^{2} \mathrm{D}\right) 5 p^{3} \mathrm{P}$ & & & 50458 & 50519 & -61 & & 1.150 \\
\hline
\end{tabular}


TABLE A. Observed and calculated levels of CoI $(3 \mathrm{~d}+4 \mathrm{~s})^{8} 4 \mathrm{p}-$ Continued

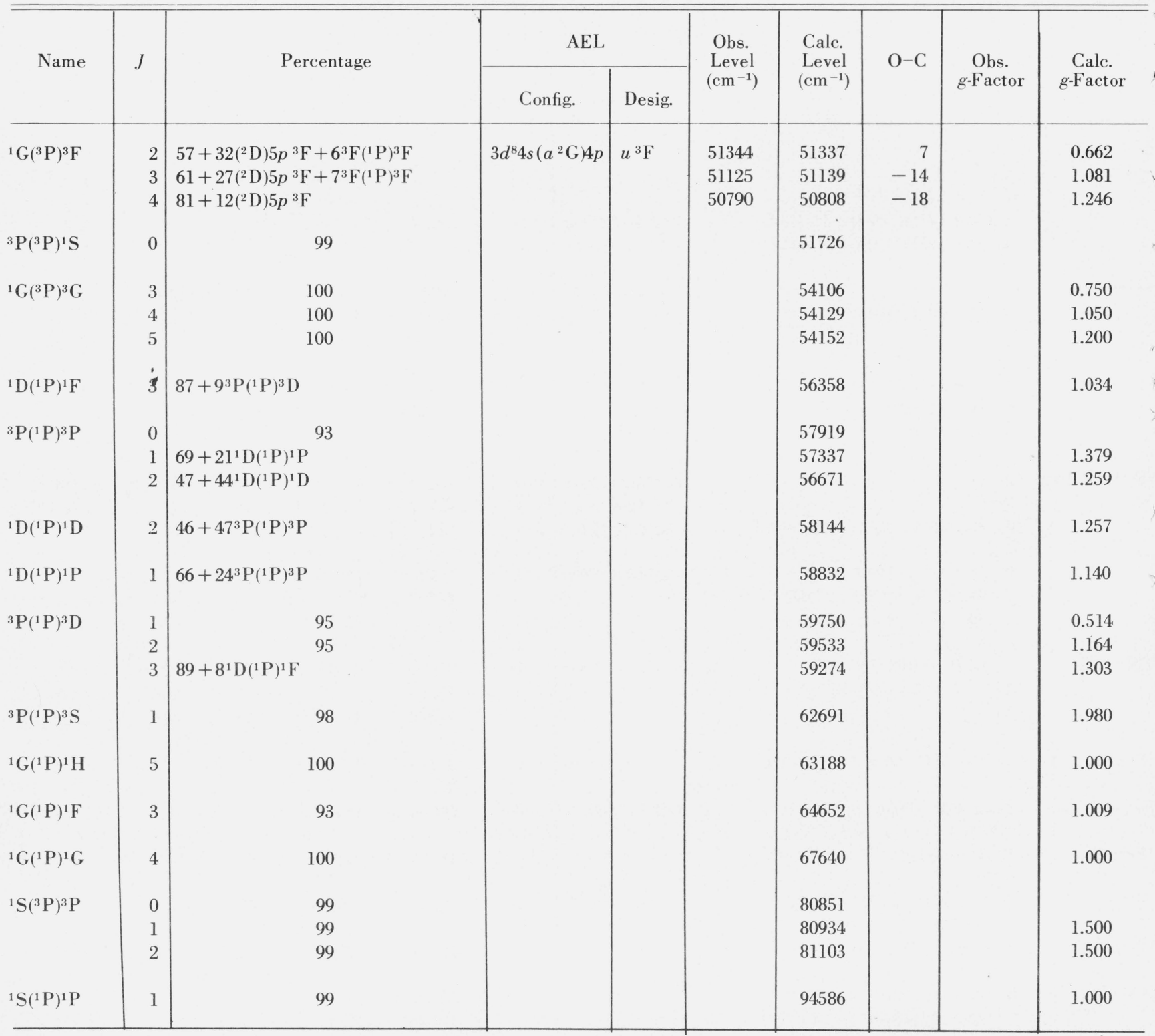

\section{References}

[1] Moore, C. E., Atomic energy levels, Nat. Bur. Stand. (U.S.), Circ. 467, Vol. II (1952). Referred to as AEL.

[2] Roth, C., J. Res. Nat. Bur. Stand. (U.S.), 73A (Phys. and Chem.), No. 5, 497 (1969).

[3] Roth, C., J. Res. Nat. Bur. Stand. (U.S.), 74A (Phys. and Chem.), No. 2, 141 (1970).

[4] Roth, C., J. Res. Nat. Bur. Stand. (U.S.), 74A (Phys. and Chem.), No. 2, 157 (1970).

[5] Roth, C., J. Res. Nat. Bur. Stand. (U.S.), 74A (Phys. and Chem.), No. 4, 507 (1970)

[6] Roth, C., J. Res. Nat. Bur. Stand. (U.S.), 74A (Phys. and Chem.), No. 2, 181 (1970).
[7] Roth, C., J. Res. Nat. Bur. Stand. (U.S.), 74A (Phys. and Chem.), No. 5, 703 (1970).

[8] Roth, C., J. Math. Phys. 9, No. 5, 686 (1968).

[9] Roth, C., J. Res. Nat. Bur. Stand. (U.S.), 73A (Phys. and Chem.), No. 6, 599 (1969).

[10] Russell, H. N., Phys. Rev. 34, 821 (1929).

[11] Bakker, Proc. Akad. Amsterdam 35, 82 (1932).

[12] Marvin, H. H., and Baragar, A. E., Phys. Rev. 43, 973 (1933).

[13] Dijkstra, H., Physica 4, 81 (1937).

[14] Lindsley, C. H., J. Opt. Soc. Am. 32, 94 (1942).

[15] Shenstone, A. G., Phys. Rev. 30, 255 (1927). 